\title{
A Large Intra-Articular Ossicle in the Knee Joint-A Rare Occurrence
}

\author{
Lokesh Rana ${ }^{1}$, Dinesh Sood ${ }^{2}$, Raman Chauhan ${ }^{3}$, Roshni Shukla ${ }^{4}$, Pooja Gurnal SR ${ }^{5}$ and Himanshu Nautiyal ${ }^{3}$ \\ ${ }^{1}$ Department of Radio-diagnosis, Dr RPGMC, India
}

${ }^{2}$ Department of Radio-diagnosis, Dr RPGMC, India

${ }^{3}$ Department of Preventive and social medicine, Dr RPGMC, India

${ }^{4}$ Department of Radio-diagnosis, Dr RPGMC, India

${ }^{5}$ Department of Anaesthesia, Dr RPGMC, India

*Corresponding author: Lokesh Rana, Senior Resident, Department of Radio-diagnosis, Dr RPGMC, Kangra at Tanda, Himachal Pradesh, India

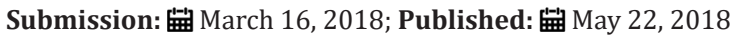

\begin{abstract}
The occurrence of an intra-articular ossicle is not rare in the knee but seldom have they achieved large size. Case report

We report a 14-year-old male who underwent a magnetization resonance imaging of the right knee joint having history of pain in the right knee for the past few months. There was no history of any trauma as such. On MR imaging we found a large intra articular ossicle in the knee joint in relation to the anterior cruciate ligament causing lifting of the ACL anterior-laterally. Intra-articular accessory ossicle of knee is a rare occurrence which can grow to size as seen in this case with significant mass effect and clinically mimic an ACL injury.
\end{abstract}

Keywords: Intraarticular ossicle; Anterior cruciate ligament

\section{Introduction}

Meniscal ossicles are uncommon, often incidental, findings on radiography and cross-sectional imaging of the knee [1,2]. The aetiology of a meniscal ossicle has not been definitively established, and congenital, traumatic, and degenerative origins have been suggested [2-4]. Its association with the posterior horn of the medial meniscus may favour a traumatic origin. Its occurrence with ACL suggests more a congenital origin [5].

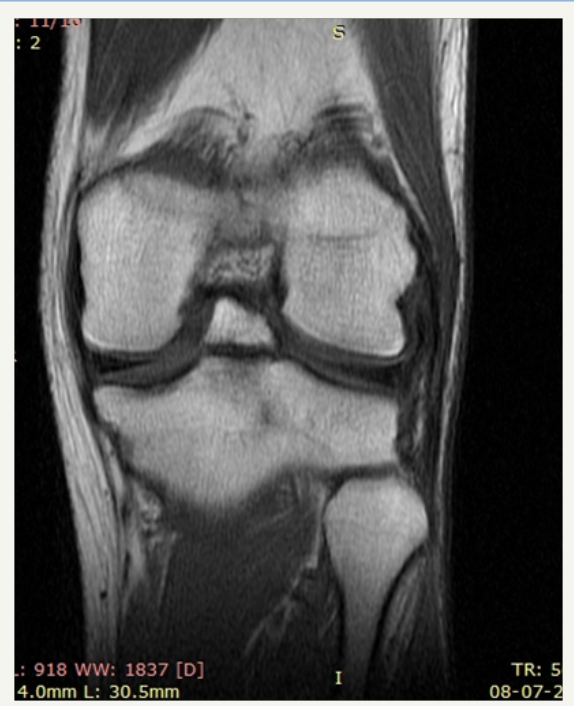

Figure 1: multiple intra-articular ossicles in coronal T1W. 


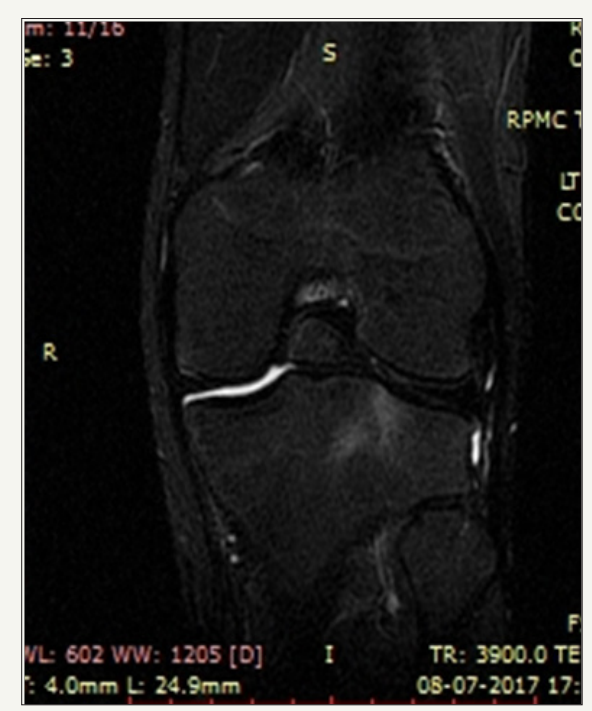

Figure 2: STIR.

Figure 3: Sagittal STIR.
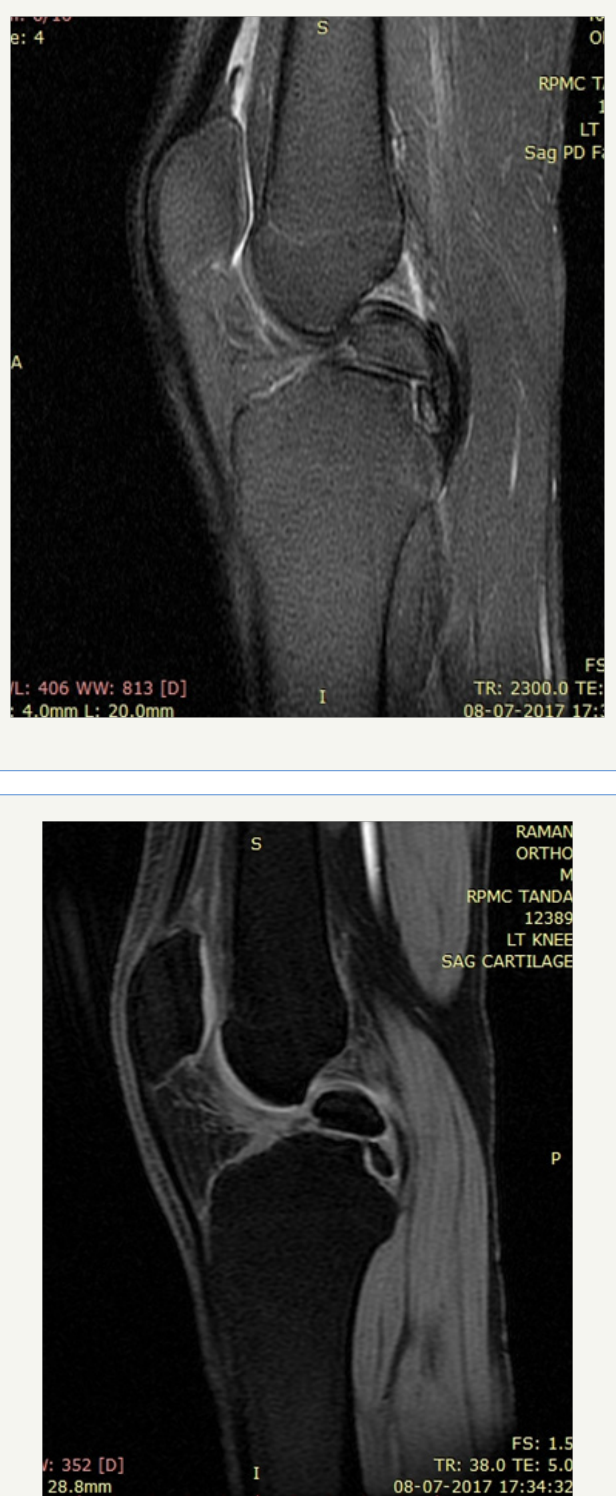

Figure 4: PD. 
We present a case of 14 year old male child who had history of pain in the right knee while climbing upstairs for long duration. There was no history of any significant trauma in the past. After clinical examination by the orthopaedician in the outpatient department patient came to our department for MRI right knee with strong clinical suspicion of ACL injury. We did MRI of right of the patient and found a large ossicle intra-articularly which was impinging the ACL. The ossicle showed the signal intensity of bone on all pulse sequences. No other pathology was noted in the right knee joint (Figure 1-5).

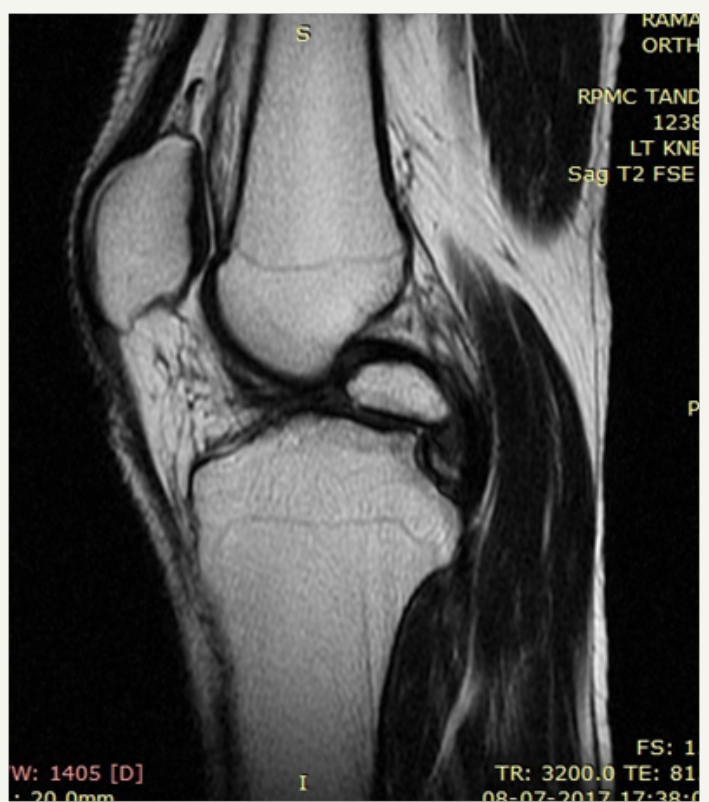

Figure 5: T1W.

\section{Discussion}

An ossicle is defined as a mature lamellar and cancellous bone with a covering of hyaline cartilage and fatty marrow within. The aetiology of a meniscal ossicle has not been definitively established so far $[1-3,6]$. It has been suggested that it may have Congenital, traumatic and degenerative origins. The existence of intraarticular ossicles in knee is not very uncommon though however its occurrence to such a large size causing mass effect to ACL is rarely mentioned in the literature [5,6]. Rohilla et al. described a symptomatic meniscal ossicle in a 25-year-old male farmer which is also seen in our case [7]. Patients with such intra-articular ossicles present with pain and on X-ray are most commonly misdiagnosed as loose bodies however clinical signs and symptoms could easily distinguish the two entities as loose bodies seldom assumes such large size and cause symtoms $[8,9]$. MRI is helpful in depicting the nature of the mass by localizing its site and showing isointensity to the normal bone marrow in all pulse sequences. It is the most useful tool to differentiate it from loose bodies, chondrocalcinosis or osteochondritis dissecans [10]. It also rules out the existence or absence of any other pathology in the joint [11-14].

\section{Conclusion}

Intra-articular ossicle in the knee joint in not a uncommon occurrence but it assuming such a large size and causing mass effect as seen in our case in the form of impingement of ACL is rarely seen in the literature.

\section{References}

1. Sarsilmaz A, Gelal F (2011) A new variation: an anterior cruciate ligament attached to the accessory ossicle. Clinical Anatomy 24(8): 991993.

2. Mellado JM, Ramos A, Salvadó E, Camins A, Danús M, et al. (2003) Accessory ossicles and sesamoid bones of the ankle and foot: imaging findings, clinical significance and differential diagnosis. EurRadiol 13(4): L164-L177.

3. Bui-Mansfield LT, Youngberg RA (1997) Intraarticular ganglia of the knee: prevalence, presentation, etiology, and management. American Journal of Roentgenology 168(1): 123-127.

4. Benthien JP, Brunner A (2010) A symptomatic sesamoid bone in the popliteus muscle (cyamella). Musculoskelet Surg 94(3): 141-144.

5. Akansel G, Inan N, Sarisoy HT, Anik Y, Akansel S (2006) Popliteus muscle sesamoid bone (cyamella): appearance on radiographs, CT and MRI. Surg Radiol Anat; 28(6): 642-645.

6. Specchiulli F, Laforgia R, Mocci A, Miolla L, Scialpi L, et al. (1995) Anterior cruciate ligament reconstruction: a comparison of 2 techniques. Clinical Orthopaedics and Related Research 311: 142-147.

7. Prabhudesai V, Richards PJ (2003) Radiological appearance as a meniscalossicle develops: a case report and review of literature. Injury 34(5): 378-382.

8. Watson JR, Roberts RE (1934) Calcification, decalcification and ossification. British Journal of Surgery 21: 461- 499.

9. Yu JS, Resnick D (1994) Meniscal ossicle: MR imaging appearance in three patients. Skeletal Radiology 23(8): 637- 639.

10. Berg EE (1991) Themeniscal ossicle: the consequence of a meniscal avulsion. Arthroscopy 7(2): 241-243. 
11. Ogilvie-Harris DJ, Sekyi-Otu A (1995) Periarticular heterotopic ossification: a complication of arthroscopic anterior cruciate ligament reconstruction using a two-incision technique. Arthroscopy 11(6): 676679.

12. Rohilla S, Yadav RK, Singh R, Devgan A, Dhaulakhandi DB (2009) Menisca ossicle Journal of Orthopaedics and Traumatology 10(3): 143-145.
13. Schnarkowski P, Tirman PF, Fuchigami KD, Crues JV, Butler MG, et al. (1995) Meniscal ossicle: radiographic and MRimaging findings. Radiology 196(1): 47-50.

14. Tsujii A, Tanaka Y, Yonetani Y, Iuchi R, Shiozaki Y, et al. (2012) Symptomatic calcification of the anterior cruciate ligament: a case report. Knee 19(3): 223-225.

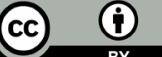

Creative Commons Attribution 4.0 International License

For possible submissions Click Here

\section{Submit Article}

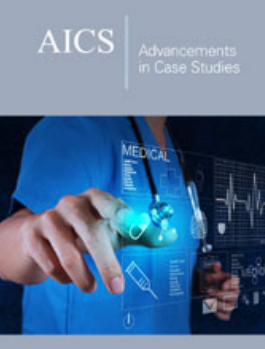

\section{Advancements in Case Studies}

\section{Benefits of Publishing with us}

- High-level peer review and editorial services

- Freely accessible online immediately upon publication

- Authors retain the copyright to their work

- Licensing it under a Creative Commons license

- Visibility through different online platforms 